\title{
SINERGIA
}

REVISTA DO INSTITUTO DE CIÊNCIAS ECONÔMICAS, ADMINISTRATIVAS E CONTÁBEIS (ICEAC)

\section{A SUSTENTABILIDADE DE EMPRESAS DE TELEFONIA: UMA ANÁLISE COM BASE NO MODELO ORIENTADO À REPRESENTAÇÃO DO PENSAMENTO HUMANO}

\author{
IVAN MAIA TOMÉ \\ LUÍS PAULO BRESCIANI"
}

\begin{abstract}
RESUMO
O objetivo fundamental é analisar se a adição de valor aos clientes segue a mesma tendência do divulgado sobre sustentabilidade pelas empresas de Telefonia, participantes do Programa Em Boa Companhia (PEBC) (BM\&F BOVESPA, 2013). Para extração do conhecimento divulgado sobre sustentabilidade socioambiental, é aplicado o Modelo Orientado à Representação Pensamento Humano - MORPH (ZAMBON, 2006). Foi utilizado um grupo de empresas que divulgam objetivos semelhantes, no caso, as empresas de Telefonia do Programa Em Boa Companhia da BM\&F BOVESPA (2013) ,- que buscam o desenvolvimento sustentável. Objetos extraídos foram inseridos no frame MORPH e foram gerados scores, dessa maneira, analisadas por variáveis qualitativas (objetos sobre sustentabilidade) e variáveis quantitativas (scores e receitas de vendas). A TIM tem score 106 , com variação positiva de $8,94 \%$ em sua receita de vendas de 2011 a 2012. A Telefônica Vivo tem score 257, com variação positiva de 14,15\%, em sua receita de vendas, de 2011 a 2012. Porém, a empresa TIM (score 106) divulga informações menos objetivas e claras com relação à empresa Telefônica Vivo (score 257), quanto à consideração e a detalhes consistentes sobre práticas de governança sustentável.
\end{abstract}

Palavras-chave: Extração de Conhecimento, Gestão do Conhecimento, Governança Corporativa, Sustentabilidade, Telefonia.

ABSTRACT

The fundamental objective is to analyze whether Telephony firms, Program In Good Company (PEBC) participants (BM\&F BOVESPA, 2013), adding value to customers follows the same trend is disclosed on sustainability. For the extraction of knowledge disclosed on socio-environmental sustainability is applied Model-Oriented Representation of Human Thought - MORPH (ZAMBON, 2006). A group of companies that disclose similar goals that is the business case Telephony Program In Good Company BM\&F BOVESPA (2013), seeking sustainable development was used. Objects extracted were incepted in frame $\mathrm{MORPH}$, scores were generated, thus, analyzed by qualitative variables (objects on sustainability) and quantitative variables (scores and sales revenue). TIM has 106 score with a positive change of $8.94 \%$ in its sales revenue from 2011 to 2012 . Telefonica Vivo score is 257, with a positive change of $14.15 \%$ in its sales revenue from 2011 to 2012. However, the company TIM (score 106) discloses less objective and clear information regarding the company Telefonica Vivo (score 257), which carries details of consistent practices for sustainable governance.

Keywords: Corporate Governance, Knowledge Extraction, Knowledge Management, Sustainability, Technology.

Recebido em: 08-02-2017 Aceito em: 20-02-2018

\section{INTRODUÇÃo}

O objetivo fundamental é analisar se a adição de valor aos clientes segue a mesma tendência do divulgado sobre sustentabilidade pelas empresas de Telefonia, participantes do Programa Em Boa Companhia (PEBC) (BM\&F BOVESPA, 2013). A adição de valor baseia-se do conceito de utilidade (ROMEIRO, 2001). É considerado útil todo bem que gera valor ou satisfação ao consumidor e, sob esse contexto, o comércio internacional, durante o último século, alavancou negócios, impulsionado pelos processos de produção em massa (PORTER, 2008). A quantidade de vendas de uma empresa reflete a satisfação dos clientes com os seus produtos (PACE; BASSO; SILVA, 2003), representando a sustentabilidade econômico-financeira.

A sociedade da informação (CASTELLS, 2003) intensificou e ampliou as relações comerciais entre os continentes. As oportunidades do livre comércio oferecem a exploração extrema da função produção. Identificada na formação de clusters industriais, a busca por reduzir custos e maximizar a produção de bens apoiou-se a partir de tecnologias. Parte-se do fato de que o volume produzido a partir das novas tecnologias

\footnotetext{
"Professor Doutor da Universidade Federal do Mato Grosso do Sul (UFMS)

"* Professor Doutor da Universidade Municipal de São Caetano do Sul (USCS) e da Fundação Getúlio Vargas (FGV)
} 
foi excedendo a demanda local, e, às vezes, a demanda regional.

Em termos de sustentabilidade socioambiental, os recursos naturais explorados, de forma intensificada, servem como matérias-primas para os clusters industriais. Essa exploração tem provocado desajustes econômicos. Como resultado, primeiramente, a degradação ambiental e, em um segundo estágio, a migração dos clusters industriais para outras áreas que ofereçam condições mais satisfatórias para a manutenção, com crescimento da atividade fabril e consequentes problemas sociais (PERRIG; CHAN, 2004).

O crescimento desorganizado da sociedade contribuiu, segundo Romeiro (2001), à perda da sustentabilidade empresarial, provocada por um problema de alocação intertemporal de recursos, entre consumo e investimento dos agentes econômicos, cuja motivação se encontra fundamental à maximização da utilidade. Contudo, como mensurar e como comparar a relação das atividades de empresas voltadas para a sustentabilidade tanto econômica como socioambiental é um desafio, e esse artigo busca cumpri-lo com a explicitação do conhecimento divulgado por um grupo de empresas que declara investir em sustentabilidade.

Seguidamente, são apresentados ativos que adicionam valor e forma de mapear essa adição, dentre os quais o Modelo Orientado à Representação do Pensamento Humano (MORPH) (ZAMBON, 2006).

\section{REFERENCIAL TEÓRICO}

A evolução da era industrial para a era do conhecimento ocorreu de uma forma gradativa, dificultando a adaptação das empresas ao novo cenário de competição. Nesta parte, discute-se sobre a construção do conhecimento individual e coletivo, no âmbito pessoal e empresarial, e sobre os instrumentos de organização desse conhecimento.

\subsection{Impacto dos Ativos Intangíveis na Competitividade}

A competitividade na sociedade industrial se baseou pela produção em massa, com as fontes de energia e com a intensa especialização dos trabalhadores. Pela sociedade do conhecimento, a competitividade se baseia pela gestão, não de recursos físicos, mas de conhecimentos provenientes das pessoas que passaram a se organizar sob outra dinâmica, de forma diferenciada à da sociedade industrial, originando a designação dos "trabalhadores do conhecimento" (DRUCKER, 2010, p. 20).

O conhecimento desses trabalhadores, focado na obtenção de resultados ao âmbito empresarial, passou a ser reconhecido como um "ativo intangível". Instalações, prédios e máquinas, bens, até então reconhecidos como únicos ativos responsáveis pela geração de valor econômico, passam a dar espaço para a capacidade de criação da vantagem competitiva (NONAKA, 2007).

O conhecimento individual contribui para a formação do conhecimento empresarial, desde que, de forma articulada, possibilite a produção e o compartilhamento de ideias que devem ser aceitas e validadas pelos participantes dos processos decisórios. A busca por instrumentos e métodos que produzam esse compartilhamento ainda é um problema a ser vencido pelas sociedades empresariais, que devem transpor a dificuldade imposta pela própria característica de intangibilidade do conhecimento.

Um desses conhecimentos é o que os indivíduos e as organizações pensam sobre sustentabilidade. De acordo com John Elkington (2002), a sustentabilidade é representada pelas dimensões ambiente, economia e sociedade. O desenvolvimento econômico traz renda para a sociedade que consome e, certamente, degrada o meio ambiente. E o equilíbrio entre essas dimensões define a renovação de um ciclo a partir de produtos e serviços tão satisfatórios às pessoas, de modo a degradar menos ambientalmente. Considerando esse fato, as Nações Unidas (UNITED NATIONS, 2001) introduziram a quarta dimensão chamada de institucional. Assim, as instituições devem ser mantidas para proporcionar as condições necessárias para a sustentabilidade.

O Quadro 1 apresenta os temas sugeridos pela Comissão de Desenvolvimento Sustentável (CSD), segundo cada dimensão. Apresentam-se as diversas formas de definir sustentabilidade. Considerando uma empresa, os temas que escolheria divulgar poderiam ser relacionados aos interesses da área de negócio que atuam ou desejam atuar. Quanto mais atendem ao tema da sustentabilidade socioambiental como instituição, maiores serão as chances de atingirem a sustentabilidade econômica de modo a equilibrar o ciclo das dimensões. Tais práticas se contabilizam como ativos intangíveis para agregar valor aos seus negócios. 
QUADRO 1 - Temas-chave sugeridos pelas prioridades dos países em teste pela CSD

\begin{tabular}{|c|c|}
\hline Social & Ambiental \\
\hline Educação & Água doce / águas subterrâneas \\
\hline Emprego & Agricultura / abastecimento seguro de alimentos \\
\hline Saúde / abastecimento de água / saneamento & Urbano \\
\hline Habitação & Zona costeira \\
\hline Bem-estar e qualidade de vida & Ambiente marinho / proteção de recifes de coral \\
\hline Herança cultural & Pescas \\
\hline Distribuição da pobreza / renda & Biodiversidade / biotecnologia \\
\hline Crime & Manejo sustentável da floresta \\
\hline População & Poluição atmosférica e depleção de ozônio \\
\hline Valores éticos e sociais & Mudança climática global / aumento do nível do mar \\
\hline Papel das mulheres & Uso sustentável dos recursos naturais \\
\hline Acesso à terra e aos recursos & Turismo sustentável \\
\hline Estrutura da comunidade & Capacidade de carga restrita \\
\hline Equidade / exclusão social & Mudança do uso da terra \\
\hline Econômico & Institucional \\
\hline $\begin{array}{l}\text { Dependência econômica / Endividamento / } \\
\text { Assistência de Desenvolvimento Oficial }\end{array}$ & Tomada de decisão integrada \\
\hline Energia & Capacidade de construção \\
\hline Consumo e produção de patentes & Ciência e tecnologia \\
\hline Gestão de resíduos & Sensibilização pública e informação \\
\hline Transporte & Convenções internacionais e cooperação \\
\hline Mineração & Governança / papel da sociedade civil \\
\hline Estrutura econômica e desenvolvimento & Quadros institucionais e legislativos \\
\hline Comércio & Preparação para desastres \\
\hline Produtividade & Participação pública \\
\hline
\end{tabular}

FONTE: Adaptado de UNITED NATIONS, 2001, p. 22

Diante da grande quantidade de informações sobre sustentabilidade, apresenta-se, como um desafio, a mensuração de quais informações podem ser consideradas pelo seu conceito. O modelo para representar e mensurar esse conhecimento é descrito a seguir, a partir do MORPH (ZAMBON, 2006).

\subsection{Modelo Orientado à Representação do Pensamento Humano - MORPH}

O Modelo Orientado à Representação do Pensamento Humano (MORPH), idealizado por Zambon (2006), consiste em uma ferramenta utilizada para explicitação do conhecimento ou do modelo mental representado por frames. Na concepção do MORPH, um frame é a menor unidade de conhecimento e representa uma ideia estruturada sobre um problema ou sobre uma observação.

Uma empresa interage com o macroambiente por meio de diversos meios e mídias, pela maioria das vezes de forma desestruturada, fazendo com que seus stakeholders sejam obrigados a buscar informações que, por vezes, se mostram desencontradas, ambíguas ou duplicadas. Na parte anterior, foi apresentada uma discussão da gestão do conhecimento, que contribui para organizar as informações esparsas em um contexto complexo, observando que, cada uma delas, age, especificamente, para gerar um determinado resultado.

Neste tópico, apresenta-se o MORPH, uma ferramenta de gestão do conhecimento que interage com diversas mídias, denominadas agentes, e revela as estruturas complexas de conhecimento, permitindo a análise da estrutura desses conhecimentos.

\subsubsection{Abordagem cognitiva: base da estrutura do MORPH}

Cognição é uma atividade mental que descreve a aquisição, o armazenamento, a transformação e a aplicação do conhecimento (MATLIN, 2004). Considera-se, também, que a abordagem cognitiva abrange os instrumentos necessários ao entendimento dos processos mentais, responsáveis pelo conhecimento dos indivíduos.

Tais processos são de extrema importância para a gestão do conhecimento, pois envolvem, desde a metacognição, que se refere ao ato de pensar sobre os próprios pensamentos, à atividade essencial à 
aprendizagem, até aos modelos mentais, presentes em apoio à decisão. Senge (2009) buscou a representação gráfica do conhecimento humano, por meio da estruturação de modelos mentais, que, segundo sua proposta, permitiria entender a lógica utilizada por indivíduos para executar suas ações nos âmbitos social e organizacional.

Em termos de aprendizado organizacional, Morecroft e Sterman (2000) defendem a construção de micromundos. Estes são representações simuláveis de modelos mentais. O estudo de micromundos nos permite analisar capacidade de atuar pela concepção do planejamento estratégico empresarial e pelos processos de melhoria contínua.

Essas iniciativas revelam que as representações gráficas de modelos mentais mais comumente utilizadas são analógicas, ou seja, preservam as características dos objetos originais, presentes no mundo real. Essa tem sido a forma mais difundida para o armazenamento das informações para posterior recuperação e emprego, como, por exemplo, os instrumentos como storytelling, compostos por imagens, sons, textos de indivíduos que participaram da solução de problemas no ambiente corporativo. Instrumentos que representam a base do aprendizado de equipes que se lançam à pesquisa de novas alternativas ou soluções são recursos empregados pelas empresas como exemplos de representações analógicas.

Segundo Santos, Belton e Howick (2008), o risco de se utilizarem representações analógicas é que se apresenta um problema e sua solução, sem que, no entanto, a arquitetura de solução do problema seja explicitada pelo modelador. Isso faz com que os modelos concebidos dessa maneira sirvam apenas para fomentar a intuição do indivíduo que busca uma nova solução, não representando, necessariamente, uma forma de se obter uma resposta segura às demandas de decisão (GARDINER; FORD, 1980).

Outra forma de representação de modelos mentais, menos discutida e fundamentada pela abordagem cognitiva, é a proposicional. A representação proposicional ou descritiva (MATLIN, 2004) é abstrata, com componentes do modelo mental. A forma de armazenamento não remete perfeitamente à realidade, mas se aproxima da forma linguística. Pelo âmbito da abordagem cognitiva, o termo "modelo mental" remete a um conjunto de objetos abstraídos de um contexto. Essa representação ocorre pelo sistema de recuperação de memória e organizada por regras semânticas, que unem a memória de longo prazo à memória de trabalho. São formados contextos por tempo suficiente para estruturação, processamento, interpretação e decisão (TENPENNY; SHOBEN, 1992).

A memória de trabalho é de curta duração e, não obstante, parte dela ainda coordena as atividades mentais permanentes, constituindo um sistema formado, segundo Baddeley (1998), por três estruturas: o circuito fonológico, o bloco de esboço visuoespacial e o executivo central (FIGURA 1).

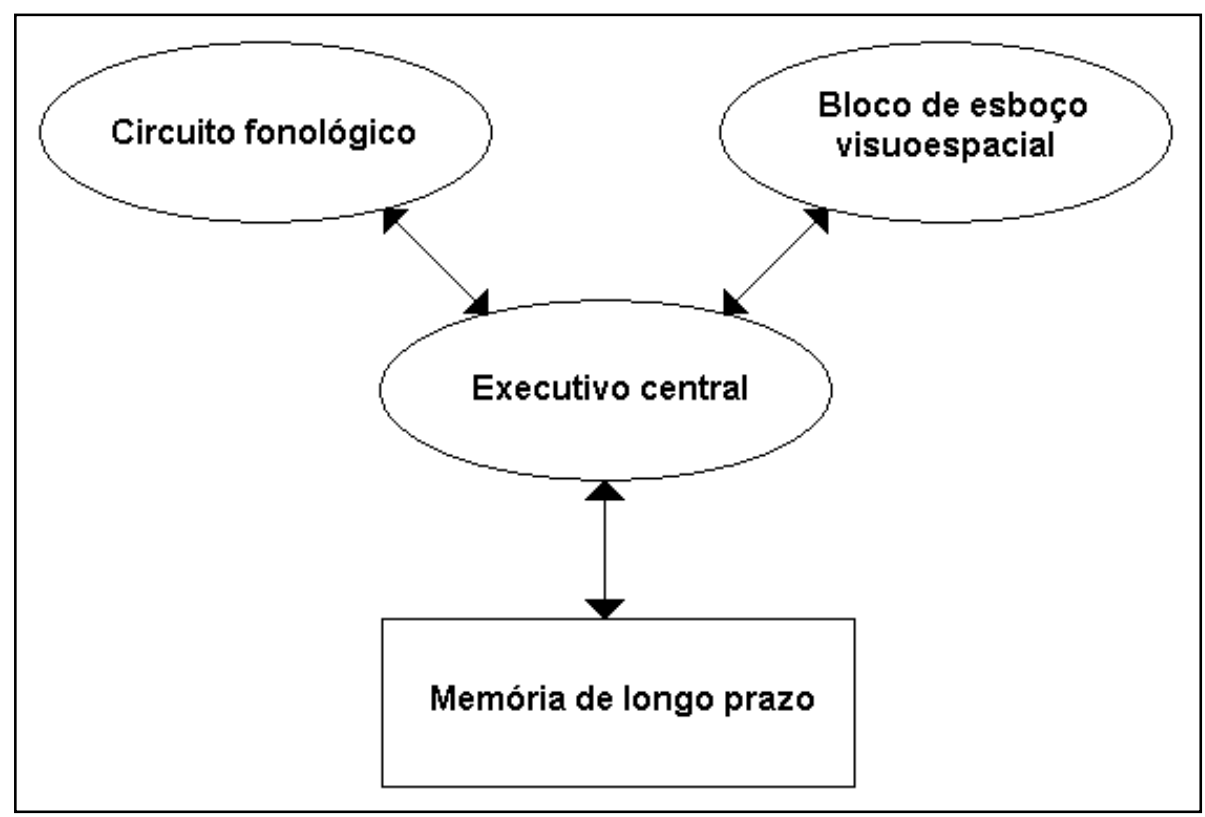

FIGURA 1 - Modelo de memória de trabalho de Baddeley

FONTE: Matlin, 2004, p. 60.

O circuito fonológico armazena um número limitado de sons por um período curto. Esses objetos não necessariamente são frutos de vocalização, mas se reportam à vocalização. Normalmente, quando indivíduos ouvem uma palavra, utilizam o circuito fonológico para interpretá-la. O mesmo ocorre quando se lembram de um objeto, que receberá o correspondente fonológico para ser interpretado, mesmo que não haja vocalização.

O bloco de esboço visuoespacial armazena, de maneira limitada, informações visuais e espaciais, 
codificadas a partir de estímulos verbais, como, por exemplo, quando se imagina uma cena a partir de uma narrativa (GATHERCOLE, 1997). O executivo central tem como objetivo integrar informações que vêm do circuito fonológico e do bloco de esboço visuoespacial, organizando tais informações, reportando-se à memória de longo prazo. Esse tipo de memória é composto pela memória semântica e pela procedural e pela episódica (GOFF; ROEDIGER, 1998). O executivo central não armazena informações, limitando-se à execução de regras.

Desse modo, a memória de trabalho compõe o sistema de recuperação da memória e, juntamente com a memória semântica, estrutura os modelos mentais, que contém os objetos abstraídos dos eventos reais por meio de estímulos distais e proximais. Um estímulo distal, recebido pela memória, permite a percepção de um objeto real em um contexto, enquanto que um estímulo proximal encerra informações do objeto real nos mecanismos dos sentidos, como audição, visão etc. (MATLIN, 2004).

Assim, os modelos mentais são estruturados a partir dos objetos percebidos pelo conjunto de estímulos recebidos, e pelas regras semânticas pertinentes ao tipo de problema observado. Essas regras restringem quais objetos farão parte do modelo mental, tendo por base o relacionamento entre esses objetos com um contexto ou cenário. Essa estrutura é definida, por Tversky e Kahneman (2000), como "decision frame".

Dessa maneira, um decision frame representa a interpretação de um contexto por um observador, sendo composto por objetos e regras semânticas que permitem interpretar um problema sob um ponto de vista. Tomar decisão é escolher uma opção de resposta entre as várias possíveis em um momento e em um determinado cenário, pressupõe o conhecimento da situação que exige a decisão, das distintas opções de ação e das consequências imediatas e futuras advindas dessa ação (BELL; KEENEY, RAIFFA, 1997).

Morecroft e Sterman (2000, p. 5) propõem a utilização de técnicas para a representação de modelos mentais, com o objetivo de obter o diferencial competitivo em diversos nichos da atividade humana:

"O conceito lógico e dominante de modelos mentais é a busca na ampla aplicabilidade na área de estratégia. Usando vários métodos de mapeamento cognitivo, os pesquisadores têm investigado as causas do declínio de negócios, a justificativa para joint ventures, e percepções de gerenciamento do posicionamento competitivo..." (MORECROFT; STERMAN, 2000, p. 5).

Uma estratégia para a representação dos modelos mentais, denominada Modelo Orientado à Representação do Pensamento Humano - MORPH (ZAMBON, 2006), pondera que os modelos mentais possam ser organizados por meio de códigos proposicionais. Considera-se que as representações mentais ocorrem pelos vínculos de ligação entre o sujeito e o objeto. Tais vínculos abrangem, não só a relação sujeito-objeto mas também a relação objeto-objeto, em uma representação sistêmica, com relações de causa, de efeito e de pesos. Esses atributos são componentes de um modelo, denominado pelo MORPH (ZAMBON, 2006) de frame - representação proposicional de um modelo mental.

\section{METODOLOGIA}

A adição de valor aos clientes, representando a sustentabilidade econômico-financeira, é aplicada pela receita de vendas. A sustentabilidade socioambiental é representada pelo que é divulgado sobre sustentabilidade pelas empresas de Telefonia, participantes do Programa Em Boa Companhia (PEBC) (BM\&F BOVESPA, 2013). Decorrente da prática de uma gestão sustentável, ações de duas empresas do setor de Telefonia por meio do MORPH, Modelo Orientado à Representação do Pensamento Humano (ZAMBON, 2006). Para a extração das variáveis necessárias, a explicitação dos modelos e a comparação entre esses são utilizados os frames que compõem o MORPH (ZAMBON, 2006) para a mensuração do que é importante para o conceito de sustentabilidade. Os frames têm a vantagem de categorizar informações de acordo com o seu nível de importância, posicionando-as em um quadrante de nove níveis - organizados mais rápido e controlável, cujas informações mais importantes obtêm maiores pontuações.

Pelo caso do PEBC, reuniram-se empresas que buscam o desenvolvimento sustentável e foram comparadas às variáveis que as empresas divulgam pelos frames do MORPH. Foram pesquisadas as empresas do PEBC durante o segundo semestre de 2011, para comparação da variação 2011 a 2012 entre os seguintes valores: valor como satisfação para os clientes das empresas, por meio das receitas de vendas (PACE; BASSO; SILVA, 2003), e o valor sustentável, por meio das práticas socioambientais das empresas.

Visando ao atendimento do objetivo fundamental, foram consideradas empresas que oferecem serviços semelhantes e buscam a sustentabilidade, caso do PEBC. Desse programa, participam várias empresas de vários setores, mas, em uma pesquisa prévia (TOMÉ, 2012), o setor de Telefonia foi o que divulgava mais conhecimentos sobre sustentabilidade pela mídia, facilitando a extração do conhecimento e a comparação entre as empresas.

Uma das empresas é a TIM, que desenvolve projetos socioambientais (TIM, 2013). A TIM teve sua receita de vendas, que se trata do valor como satisfação adicionada aos clientes, aumentada de $\mathrm{R} \$$ 
17.085.977, em 2011, para $R \$ 18.763 .947$, durante 2012, uma variação positiva de 8,94\% (BM\&F BOVESPA, 2013). Durante março de 1999, a TIM (2013), Telecom Itália Mobile, passou a controlar a companhia brasileira Intelig.

A outra empresa é a Telefônica, detentora da marca Vivo, por isso, pelo decorrer do trabalho, a empresa será chamada de Telefônica Vivo. A empresa utiliza de atitude sustentável para conquistar seus stakeholders (TELEFÔNICA VIVO, 2013). Durante 2011, sua receita foi de $\mathrm{R} \$ 29.128 .740$ e aumentou para $\mathrm{R} \$ 33.931 .422$ durante 2012, um acréscimo de 14,15\% (BM\&F BOVESPA, 2013). A Telefônica Vivo (2013) foi constituída durante maio de 1998.

As duas empresas tiveram variações de receita positivas de 2011 a 2012. São empresas exemplares, porque buscam evitar o conflito de interesses entre os empresários e os acionistas (SILVEIRA, 2002). Participam de índices voltados à sustentabilidade, como o Índice de Sustentabilidade Empresarial (ISE) (BM\&F BOVESPA, 2013). Nesse cenário, será verificada como foi a contribuição do valor sustentável para esse aumento.

Com o fim de compor o MORPH, é preciso definir a proposição $(P)$, extrair objetos e inseri-los em frames. Para complementar a pesquisa, também foram extraídos critérios, definidos valores para as zonas dos frames, apresenta-se como esses valores são modificados a partir dos relacionamentos entre objetos. $\mathrm{A}$ extração é, exclusivamente, de objetos relacionados à sustentabilidade e, como primeiro procedimento do MORPH, destacada a utilização da seguinte $P$ :

"As práticas de governança sustentável e, mais especificamente, as práticas socioambientais adicionam valor aos stakeholders?" (TOMÉ; BRESCIANI, 2015, p. 32).

A pesquisa, para descrever o que divulgam sobre $P$, se desdobrou em três fases:

i) extração de critérios e objetos, a partir da divisão de P (COSTA, 2012);

ii) composição dos modelos mentais, em frames MORPH, da TIM e da Telefônica Vivo sobre práticas de sustentabilidade;

iii) comparação entre o valor adicionado pelas empresas e o valor sustentável, por meio das práticas socioambientais das empresas.

\section{RESULTADOS E ANÁLISES}

Primeiramente, é analisada a divulgação de informações ligadas à sustentabilidade socioambiental e, posteriormente, a comparação com o desempenho econômico das empresas pelas suas receitas.

Para composição dos frames do Modelo Orientado à Representação do Pensamento Humano MORPH (ZAMBON, 2006), foi aplicada a regra de extração de Costa (2012) nos próximos QUADROS (1-4), com o número da ordem de extração (Nr.), perguntas (Perg.), conceitos (BARON; SHANE, 2007) que fazem com que haja a extração de critérios com as respostas (Resp.) às perguntas completas (Perg.) e extraídos os critérios e objetos no site da empresa TIM (2013), representados pelas respostas e, necessariamente, podem não representar a realidade.

QUADRO 1 - Regras e aplicação da extração de critérios do site da empresa TIM

\begin{tabular}{|c|c|c|c|c|}
\hline $\mathrm{Nr}$. & Perg. & Conceito & Resp. & Critério \\
\hline 1 & $\begin{array}{l}\text { Como se } \\
\text { define... }\end{array}$ & $\begin{array}{l}\text { Práticas gerais de } \\
\text { governança } \\
\text { sustentável? }\end{array}$ & Com... & $\begin{array}{c}\text { Observação da ética na divulgação de fatos } \\
\text { relevantes }\end{array}$ \\
\hline 2 & $\begin{array}{l}\text { Como se } \\
\text { define... }\end{array}$ & $\begin{array}{l}\text { Práticas gerais de } \\
\text { governança } \\
\text { sustentável? }\end{array}$ & Com... & $\begin{array}{c}\text { Observação da ética na divulgação de fatos } \\
\text { relevantes }\end{array}$ \\
\hline 3 & $\begin{array}{l}\text { Como se } \\
\text { define... }\end{array}$ & $\begin{array}{c}\text { Práticas } \\
\text { socioambientais? }\end{array}$ & Com... & $\begin{array}{l}\text { Observação do equilíbrio econômico com as } \\
\text { expectativas sociais e preservação ambiental }\end{array}$ \\
\hline 4 & $\begin{array}{l}\text { Como se } \\
\text { define... }\end{array}$ & $\begin{array}{l}\text { Práticas } \\
\text { socioambientais? }\end{array}$ & Co & $\begin{array}{l}\text { Observação do equilíbrio econômico com as } \\
\text { expectativas sociais e preservação ambiental }\end{array}$ \\
\hline 5 & $\begin{array}{l}\text { Como se } \\
\text { define... }\end{array}$ & $\begin{array}{l}\text { Práticas } \\
\text { socioambientais? }\end{array}$ & Com... & $\begin{array}{c}\text { Compromissos com divulgação aos stakeholders } \\
\text { sob a ética de relacionamento }\end{array}$ \\
\hline 6 & $\begin{array}{l}\text { Como se } \\
\text { define... }\end{array}$ & $\begin{array}{l}\text { Adição de valor aos } \\
\text { stakeholders? }\end{array}$ & Com... & $\begin{array}{l}\text { Proporcionar a rapidez em soluções para } \\
\text { atendimento das demandas }\end{array}$ \\
\hline 7 & $\begin{array}{l}\text { Como se } \\
\text { define... }\end{array}$ & $\begin{array}{l}\text { Adição de valor aos } \\
\text { stakeholders? }\end{array}$ & Com... & $\begin{array}{c}\text { Meios de ascensão com políticas claras de } \\
\text { recursos humanos }\end{array}$ \\
\hline 8 & $\begin{array}{l}\text { Como se } \\
\text { define... }\end{array}$ & $\begin{array}{l}\text { Adição de valor aos } \\
\text { stakeholders? }\end{array}$ & Com... & $\begin{array}{l}\text { Utilização de meios digitais para disseminação da } \\
\text { informação }\end{array}$ \\
\hline
\end{tabular}

Fonte: A pesquisa do autor. 
QUADRO 2 - Regras e aplicação da extração de objetos do site da empresa TIM

\begin{tabular}{|c|c|c|c|c|c|c|}
\hline Nr. & Conj. & Critério & Verbo & Conceito & Prep. & Objeto \\
\hline 2 & Como & $\begin{array}{l}\text { Observação da ética na } \\
\text { divulgação de fatos } \\
\text { relevantes } \\
\text { Observação da ética na } \\
\text { divulgação de fatos } \\
\text { relevantes }\end{array}$ & define & $\begin{array}{l}\text { Práticas gerais de } \\
\text { governança } \\
\text { sustentável? } \\
\text { Práticas gerais de } \\
\text { governança } \\
\text { sustentável? }\end{array}$ & Com... & $\begin{array}{c}\text { Divulgação da } \\
\text { evolução } \\
\text { patrimonial } \\
\text { Respeito às regras } \\
\text { de mercado }\end{array}$ \\
\hline 3 & Como & $\begin{array}{l}\text { Observação do equilíbrio } \\
\text { econômico com as } \\
\text { expectativas sociais e } \\
\text { preservacão ambiental }\end{array}$ & define & $\begin{array}{c}\text { Práticas } \\
\text { socioambientais? }\end{array}$ & Com... & $\begin{array}{l}\text { Manutenção } \\
\text { central dos } \\
\text { resultados }\end{array}$ \\
\hline 4 & Como & $\begin{array}{l}\text { Observação do equilíbrio } \\
\text { econômico com as } \\
\text { expectativas sociais e } \\
\text { preservação ambiental }\end{array}$ & define & $\begin{array}{c}\text { Práticas } \\
\text { socioambientais? }\end{array}$ & Com... & $\begin{array}{c}\text { Canal de coleta de } \\
\text { ideias }\end{array}$ \\
\hline 5 & Como & $\begin{array}{l}\text { Compromissos com } \\
\text { divulgação aos } \\
\text { stakeholders sob ética } \\
\text { de relacionamento }\end{array}$ & define & $\begin{array}{c}\text { Práticas } \\
\text { socioambientais? }\end{array}$ & Com... & $\begin{array}{l}\text { Adesão ao Pacto } \\
\text { Global da ONU }\end{array}$ \\
\hline 6 & Como & $\begin{array}{c}\text { Proporcionar a rapidez } \\
\text { em soluções para } \\
\text { atendimento das } \\
\text { demandas }\end{array}$ & define & $\begin{array}{l}\text { Adição de valor } \\
\text { aos stakeholders? }\end{array}$ & Com... & Timing de Mercado \\
\hline 7 & Como & $\begin{array}{l}\text { Meios de ascensão com } \\
\text { políticas claras de } \\
\text { recursos humanos }\end{array}$ & define & $\begin{array}{l}\text { Adição de valor } \\
\text { aos stakeholders? }\end{array}$ & Com... & $\begin{array}{c}\text { Plano de carreira } \\
\text { para os } \\
\text { colaboradores }\end{array}$ \\
\hline 8 & Como & $\begin{array}{l}\text { Utilização de meios } \\
\text { digitais para } \\
\text { disseminação da } \\
\text { informação }\end{array}$ & define & $\begin{array}{l}\text { Adição de valor } \\
\text { aos stakeholders? }\end{array}$ & Com... & $\begin{array}{l}\text { Indicadores de } \\
\text { resultado }\end{array}$ \\
\hline
\end{tabular}

FONTE: A pesquisa do autor.

As mesmas regras dos QUADROS 1 e 2 são aplicadas no QUADROS 3 e 4 a partir do site da Empresa Telefônica Vivo (2013).

QUADRO 3 - Regras e aplicação da extração de critérios do site da empresa Telefônica Vivo

\begin{tabular}{|c|c|c|c|c|}
\hline $\mathrm{Nr}$. & Perg. & Conceito & Resp. & Critério \\
\hline 1 & $\begin{array}{l}\text { Como se } \\
\text { define... }\end{array}$ & $\begin{array}{l}\text { Práticas gerais de } \\
\text { governança sustentável? }\end{array}$ & Com... & $\begin{array}{c}\text { Estabelecimento de normas com } \\
\text { foco na Comissão de Valores } \\
\text { Mobiliários (CVM) }\end{array}$ \\
\hline 2 & $\begin{array}{l}\text { Como se } \\
\text { define... }\end{array}$ & $\begin{array}{c}\text { Práticas gerais de } \\
\text { governança sustentável? }\end{array}$ & Com... & $\begin{array}{c}\text { Ampla divulgação de informações ao } \\
\text { mercado e aos acionistas }\end{array}$ \\
\hline 3 & $\begin{array}{l}\text { Como se } \\
\text { define... }\end{array}$ & $\begin{array}{l}\text { Práticas gerais de } \\
\text { governança sustentável? }\end{array}$ & Com... & $\begin{array}{c}\text { Ampla divulgação de informações ao } \\
\text { mercado e aos acionistas }\end{array}$ \\
\hline 4 & $\begin{array}{l}\text { Como se } \\
\text { define... }\end{array}$ & Práticas socioambientais? & Com. & $\begin{array}{l}\text { Organização de políticas de } \\
\text { responsabilidade socioambiental }\end{array}$ \\
\hline 5 & $\begin{array}{l}\text { Como se } \\
\text { define... }\end{array}$ & Práticas socioambientais? & Com... & $\begin{array}{l}\text { Organização de políticas de } \\
\text { responsabilidade socioambiental }\end{array}$ \\
\hline 6 & $\begin{array}{l}\text { Como se } \\
\text { define... }\end{array}$ & Práticas socioambientais? & Com... & Inclusão de pessoas com deficiência \\
\hline 7 & $\begin{array}{l}\text { Como se } \\
\text { define... }\end{array}$ & Práticas socioambientais? & Com... & Divulgação ações sociais \\
\hline 8 & $\begin{array}{l}\text { Como se } \\
\text { define... }\end{array}$ & $\begin{array}{l}\text { Adição de valor aos } \\
\text { stakeholders? }\end{array}$ & Com... & Portal de informação ao mercado \\
\hline 9 & $\begin{array}{l}\text { Como se } \\
\text { define... }\end{array}$ & $\begin{array}{l}\text { Adição de valor aos } \\
\text { stakeholders? }\end{array}$ & Com... & $\begin{array}{l}\text { Ampliação da penetração de } \\
\text { atendimento }\end{array}$ \\
\hline
\end{tabular}

FONTE: A pesquisa do autor. 
QUADRO 4 - Regras e aplicação da extração de objetos do site da empresa Telefônica Vivo

\begin{tabular}{|c|c|c|c|c|c|c|}
\hline Nr. & Conj. & Critério & Verbo & Conceito & Prep. & Objeto \\
\hline 1 & Como & $\begin{array}{l}\text { Estabelecimento de } \\
\text { normas com foco na } \\
\text { CVM }\end{array}$ & define & $\begin{array}{l}\text { Práticas gerais de } \\
\text { governança } \\
\text { sustentável? }\end{array}$ & Com... & $\begin{array}{c}\text { Comitê de } \\
\text { divulgação de } \\
\text { informações } \\
\text { relevantes }\end{array}$ \\
\hline 2 & Como & $\begin{array}{c}\text { Ampla divulgação de } \\
\text { informações ao mercado } \\
\text { e aos acionistas }\end{array}$ & define & $\begin{array}{l}\text { Práticas gerais de } \\
\text { governança } \\
\text { sustentável? }\end{array}$ & Com... & $\begin{array}{l}\text { Indicadores de } \\
\text { resultado }\end{array}$ \\
\hline 3 & Como & $\begin{array}{c}\text { Ampla divulgação de } \\
\text { informações ao mercado } \\
\text { e aos acionistas }\end{array}$ & define & $\begin{array}{l}\text { Práticas gerais de } \\
\text { governança } \\
\text { sustentável? }\end{array}$ & Com... & $\begin{array}{c}\text { Portal de } \\
\text { informações para } \\
\text { os stakeholders }\end{array}$ \\
\hline 4 & Como & $\begin{array}{l}\text { Organização de políticas } \\
\text { de responsabilidade } \\
\text { socioambiental }\end{array}$ & define & $\begin{array}{c}\text { Práticas } \\
\text { socioambientais? }\end{array}$ & Com... & $\begin{array}{c}\text { Rede } \\
\text { colaborativa de } \\
\text { educação }\end{array}$ \\
\hline 5 & Como & $\begin{array}{l}\text { Organização de políticas } \\
\text { de responsabilidade } \\
\text { socioambiental }\end{array}$ & define & $\begin{array}{c}\text { Práticas } \\
\text { socioambientais? }\end{array}$ & Com... & $\begin{array}{l}\text { Projetos de } \\
\text { desenvolvimento } \\
\text { regional }\end{array}$ \\
\hline 6 & Como & $\begin{array}{l}\text { Inclusão de pessoas } \\
\text { com deficiência }\end{array}$ & define & $\begin{array}{c}\text { Práticas } \\
\text { socioambientais? }\end{array}$ & Com... & $\begin{array}{l}\text { Acessibilidade } \\
\text { com áudio- } \\
\text { descrição }\end{array}$ \\
\hline 7 & Como & $\begin{array}{l}\text { Divulgação ações } \\
\text { sociais }\end{array}$ & define & $\begin{array}{c}\text { Práticas } \\
\text { socioambientais? }\end{array}$ & Com... & $\begin{array}{l}\text { Alertas SMS } \\
\text { Social }\end{array}$ \\
\hline 8 & Como & $\begin{array}{c}\text { Portal de informação ao } \\
\text { mercado }\end{array}$ & define & $\begin{array}{l}\text { Adição de valor } \\
\text { aos stakeholders? }\end{array}$ & Com... & $\begin{array}{l}\text { Indicadores de } \\
\text { mercado }\end{array}$ \\
\hline 9 & Como & $\begin{array}{l}\text { Ampliação da } \\
\text { penetração de } \\
\text { atendimento }\end{array}$ & define & $\begin{array}{l}\text { Adição de valor } \\
\text { aos stakeholders? }\end{array}$ & Com... & $\begin{array}{l}\text { Ampliação da } \\
\text { conectividade }\end{array}$ \\
\hline
\end{tabular}

FONTE: A pesquisa do autor.

Com os objetos extraídos, esses são posicionados e relacionados em frames, de acordo com o juízo de valor do pesquisador. A regra para quantificar os relacionamentos segue a atribuição do valor para as zonas do frame como critério adotado por Zambon (2006). Este autor utiliza da escala de Saaty (SAATY; SODENKAMP, 2010), em que os valores de 1 a 9 representam proporcionalmente a importância de cada zona na explicação da proposição $(\mathrm{P})$, composto pelos conceitos já definidos, conforme designado na FIGURA 2.

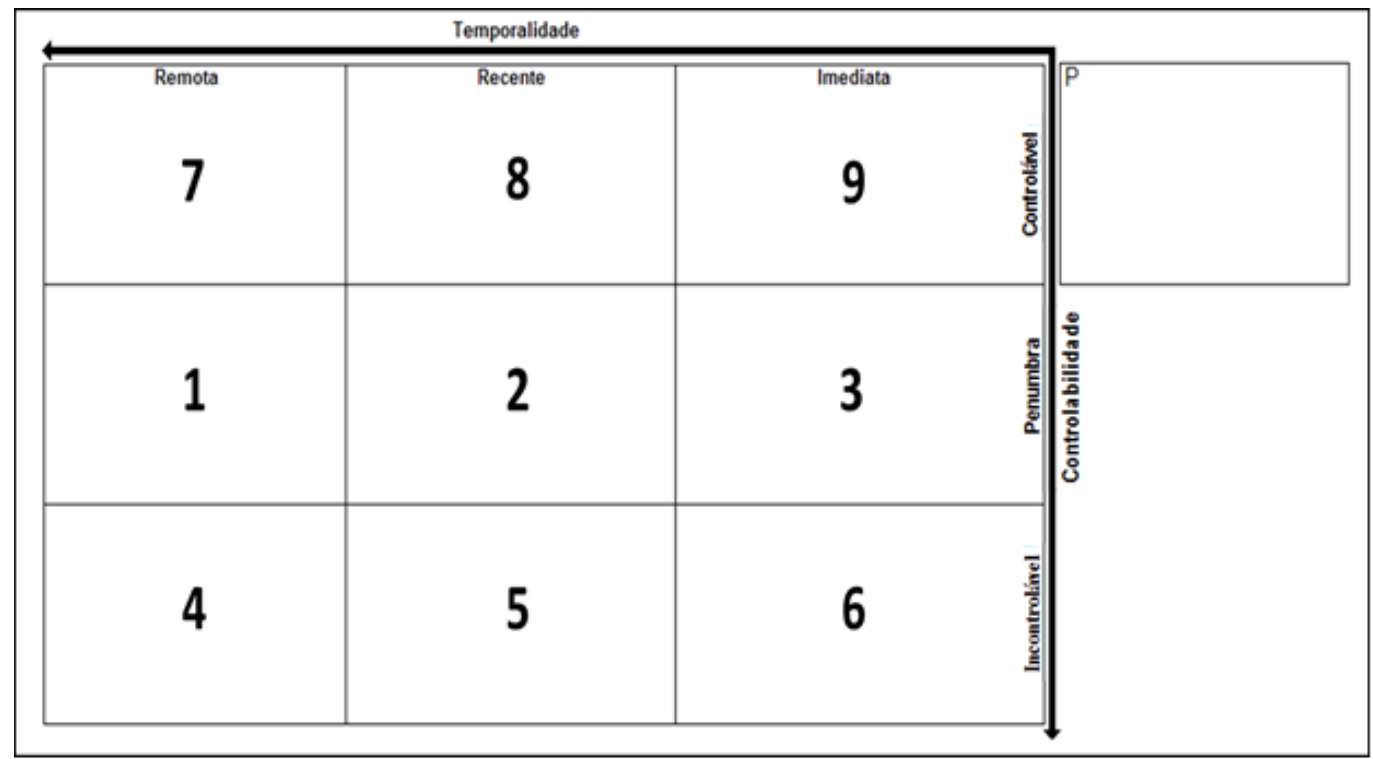

FIGURA 2 - Definição de valores para as zonas de um frame MORPH

FONTE: A pesquisa do autor.

Dessa maneira, um objeto posicionado em uma zona, cujos eixos se intersectam como controlável e recente, terá o valor 8. Entretanto, um frame MORPH (ZAMBON, 2006) é composto de relacionamentos, e 
não de objetos isolados. Esses relacionamentos são considerados sob duas tipologias: relacionamentos de cooperação e relacionamentos de competição (LAPP; OSSIMITZ, 2007).

Para os relacionamentos de cooperação, o MORPH (2011) considera duas possibilidades de ocorrência:

i) dois ou mais objetos com influência de REFORÇO sobre um terceiro objeto provocarão, neste terceiro, uma amplificação de forças, igual à soma das forças de todos os objetos. Assim, se $O b_{z}=9$, influenciado por $O b_{x}=8$ e $O b_{y}=2$, resultará em um valor para $O b_{z}=9+2+8=19$;

ii) dois ou mais objetos com influência de BALANCEAMENTO sobre um terceiro objeto convergirão suas forças sobre esse terceiro, de forma que prevaleça a média de todas as forças. Como exemplo, sendo $O b_{z}=9$, influenciado por $O b_{x}=8$ e $O b_{y}=2$, essa relação resultará em $O b_{z}=(9+2+$ $8) / 3=6,33$.

Para os relacionamentos de competição, existem três possibilidades de ocorrência:

iii) no caso de dois ou mais objetos influenciando um terceiro, sendo o de maior valor (dominante) $\boldsymbol{B}$, ocorrerá um nivelamento de forças com a força dominante. Por exemplo, se $O b_{z}=9$ influenc iado por $O b_{x}(B)=8$ e $O b_{y}(R)=2$, a força dominante mudará o valor do objeto inicial, ficando $O b_{z}=8$;

iv) se dois ou mais objetos influenciarem um terceiro, sendo a força dominante $(\boldsymbol{R})$, seguindo as mesmas características, provocarão, neste terceiro, uma amplificação igual à diferença das forças incidentes. Por exemplo, sendo $O b_{z}=9$ influenciado por $O b_{x}(R)=8$ e $O b_{y}(B)=2$, ocorrerá que $O b_{z}=$ $9+(8-2)=15$

v) se dois ou mais objetos de forças equivalentes, que por isso se competem, influenciarem um terceiro, então, o objeto não receberá o efeito das forças incidentes, que se anulam. Como exemplo, sendo $O b_{z}=9$, influenciado por $O b_{x}(R)=8$ e $O b_{y}(B)=8$, então, $O b_{z}=9$.

Com base nessas regras, há valores quantificáveis aos frames (score), que torna possível identificar similaridades entre as estruturas e a possibilidade de analisar objetos qualitativos com medidas quantitativas.

Os objetos extraídos procuram responder, da forma mais direta e controlável possível, à proposição P. Quanto mais diretos os significados dos objetos são, mais o seu posicionamento fica dentro ou próximo da área que tem como descrição Imediata e Controlável. Esse fato ocorre com o objeto Canal de Coleta Ideias na FIGURA 3. Novas ideias podem ser práticas que adicionam valor mais, diretamente, para os stakeholders, do que a Divulgação da Evolução Patrimonial e, ainda mais, do que a Adesão ao Pacto global da $\mathrm{ONU}$, que pode demandar muito mais procedimentos para responder $\mathrm{P}$.

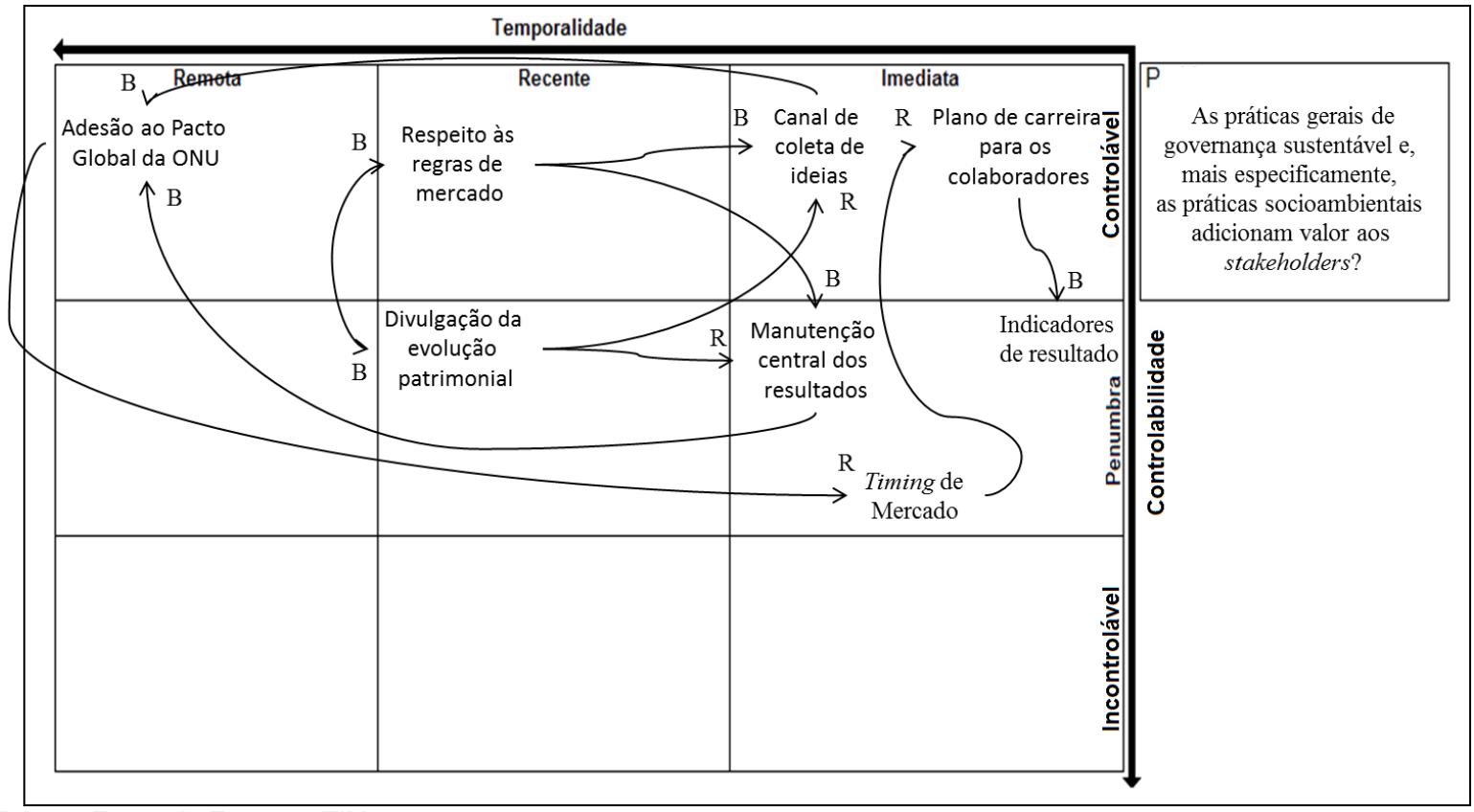

FIGURA 3 - Frame da Empresa TIM

FONTE: A pesquisa do autor.

Dentre os oito objetos do frame da empresa TIM (FIGURA 3), metade se posicionam na área Controlável pela empresa, de acordo com o contexto que extraí. Somente dois objetos estão coincidindo com a área Imediata, modificando melhor P. A outra metade de objetos está numa área de Penumbra, não 
sabendo se é ou não controlável pela empresa, o que fez com que a soma dos cálculos dos objetos e seus relacionamentos resultassem numa pontuação, ou score, menor.

O QUADRO 5 apresenta os cálculos do frame da empresa TIM (FIGURA 3), passo a passo, em miniframes. Separados pela linha em negrito, os miniframes apresentam a quantidade de objetos por zona, inicialmente, com os valores das zonas de origem. Os passos de cada cálculo dos relacionamentos equilibrando e adicionando os valores dos objetos. O valor do frame é dado pela soma dos valores no último miniframe, que apresentam os resultados dos valores dos objetos, já calculados a cada relacionamento.

QUADRO 5 - Cálculos por relacionamento do frame da Empresa TIM, com score 106

\begin{tabular}{|r|r|rr|r|r|rr|r|r|rr|r|r|rr|}
\hline 7 & 8 & 9 & 9 & 7 & 8 & 9 & 9 & 7 & 8 & 8 & 9 & 11 & 8 & 8 & 9 \\
\hline & 2 & 3 & 3 & & 8 & 3 & 3 & & 8 & 11 & 3 & & 8 & 11 & 3 \\
& & & & & & 3 & & & & 3 & & & 3 \\
\hline & & & & & & & & & & & & & & & \\
\hline 11 & 8 & 8 & 9 & 11 & 8 & 8 & 23 & 11 & 8 & 8 & 23 & & & & \\
& 8 & 11 & 3 & & 8 & 11 & 3 & & 8 & 11 & 23 & & & & \\
& & & 14 & & & & 14 & & & & & & \\
\hline & & & & & & & & & & & & & & & \\
\hline
\end{tabular}

FONTE: A pesquisa do autor.

Pela FIGURA 4, destacam-se os Indicadores de Resultados (IRs) que podem satisfazer mais os stakeholders do que o Comitê de Divulgação de Informações. Os IRs se destacam mais que os Alertas SMS Social, pois os SMS enviados não apresentam tanta repercussão quanto os próprios IRs. Os IRs podem transmitir melhores resultados das empresas em vários canais de informação, tais como jornais, internet e outros, ao invés de somente o celular que é um objeto utilizado de Alertas de SMS (TIM, 2013).

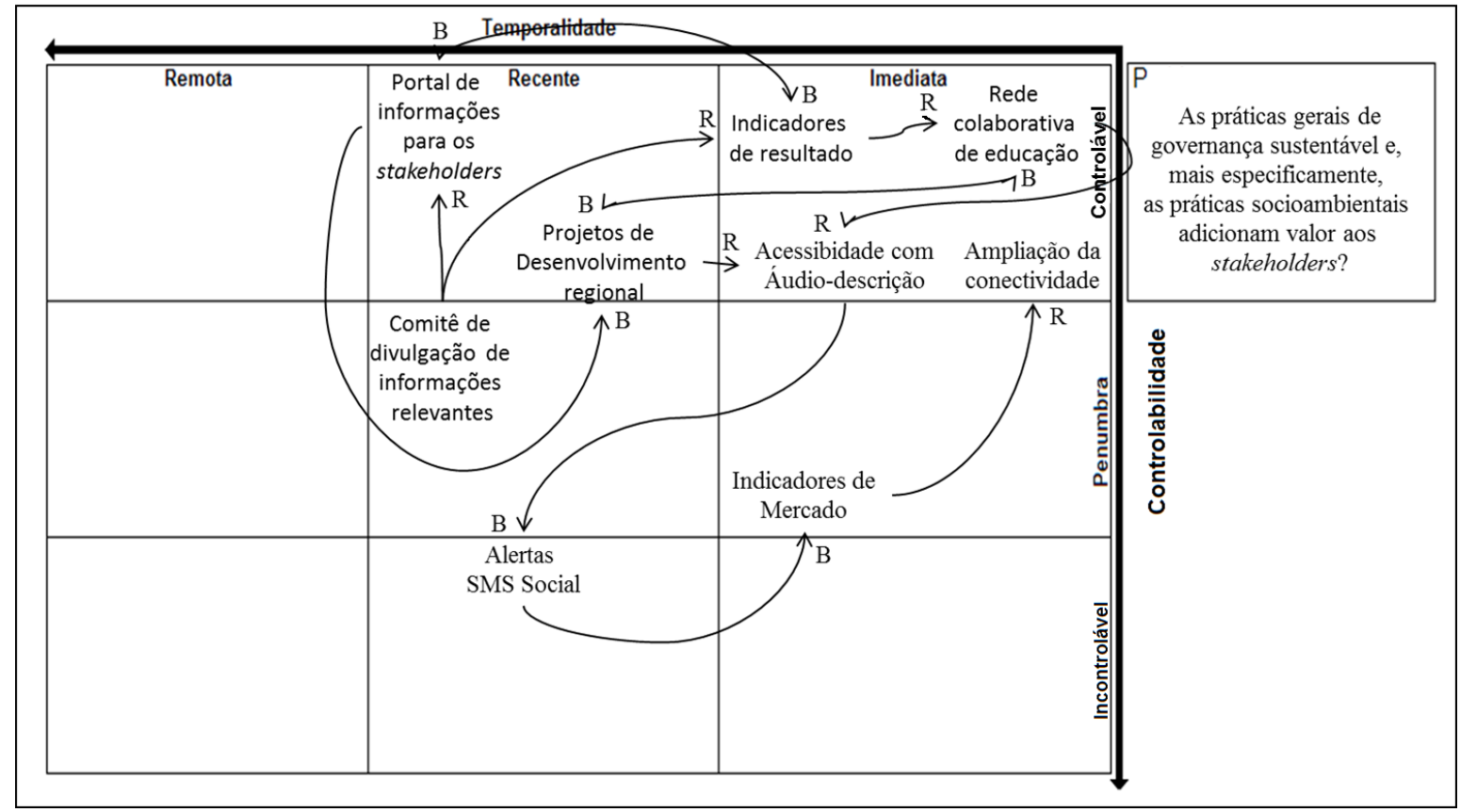

FIGURA 4 - Frame da empresa Telefônica Vivo

FONTE: A pesquisa do autor.

Dentre os nove objetos do frame da empresa Telefônica Vivo, somente um objeto está na área Incontrolável pela empresa. Dois objetos estão na área de Penumbra; a grande maioria, seis objetos, estão na área Controlável. Quatro desses seis objetos estão coincidindo imediatamente para a modificação de P, contribuindo para um score maior.

O QUADRO 6 apresenta os cálculos para o score, passo a passo, do frame da empresa Telefônica Vivo (FIGURA 4). O valor do frame é dado pela soma dos valores resultantes no último miniframe. 
QUADRO 6 - Cálculos por relacionamento do frame da Empresa Telefônica Vivo com score 257

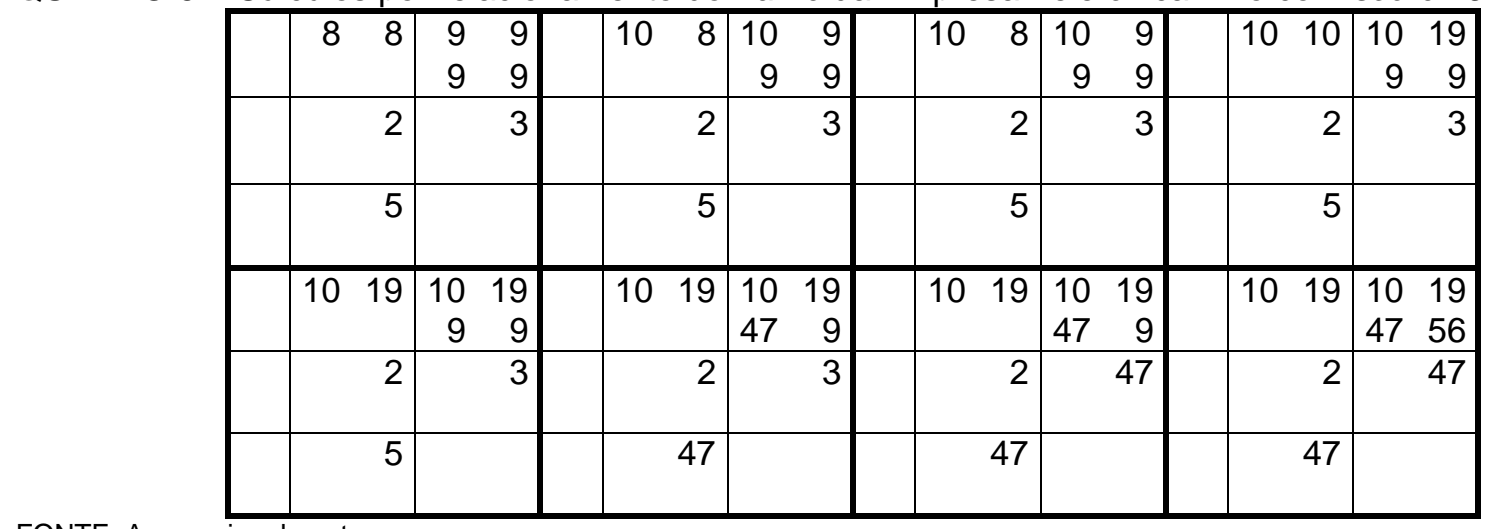

FONTE: A pesquisa do autor.

Por meio das regras para quantificar os relacionamentos entre os objetos dos frames, é possível perceber que a empresa TIM (score 106) não responde melhor, em termos de temporalidade e de controlabilidade, ao contrário da empresa Telefônica Vivo (score 257).

A grande parte de relacionamentos entre objetos localizados próximos com a intermediação Imediata e Controlável, demonstradas nas FIGURAS 3 e 4, são os argumentos para altos scores, diante da prática de ações de sustentabilidade, ao descrever e analisar os resultados. A partir do posicionamento dos objetos, foram gerados scores que apresentam o mesmo curso positivo dos valores de suas receitas de vendas (BM\&F BOVESPA, 2013):

- TIM: score 106, com menos objetos e muitos deles posicionados na área de Penumbra, com variação positiva de $8,94 \%$ em sua receita de vendas de 2011 a 2012;

- Telefônica Vivo: score 257, com mais objetos, e a maioria deles posicionados na área Controlável pela empresa, com variação positiva de 14,15\% em sua receita de vendas de 2011 a 2012.

A partir dessa análise, verifica-se que as duas empresas analisadas adicionam valor aos seus stakeholders, porque tiveram um score maior que zero. Porém, a empresa TIM (score 106) divulga informações menos objetivas e claras com relação à empresa Telefônica Vivo (score 257), quanto à modificação da proposição $(\mathrm{P})$, que carrega detalhes consistentes sobre práticas de governança sustentável. Prevaleceu a empresa mais experiente (Telefônica Vivo - constituída em 1998, e a TIM 1999). Portanto, quanto maior o seu score, mais transparente pode ser a empresa com relação à sustentabilidade.

\section{CONCLUSÃO}

A busca de produtos e serviços que tem como diferencial a sustentabilidade intensificou as divulgações de informações sobre o tema. Dentre as empresas pesquisadas, a Vivo divulgou maior número de informações que atingem a demanda sustentável da concorrente, a Tim. Aliando o conceito de satisfação com a quantidade de vendas, o cliente da Vivo respondeu às maiores iniciativas da empresa com maior consumo de seus serviços. Diante de clientes cada vez mais exigentes, diferenciais, tais como o valor contemporâneo da sustentabilidade, podem intensificar o valor econômico-financeiro das empresas.

É notória a preocupação das empresas ao divulgar sua visão, especificamente, com relação à sustentabilidade, contudo não há um padrão entre as empresas quando a intenção é a divulgação de conhecimento. Diante desse fato, os frames foram capazes de mensurar esse conhecimento de forma a nivelar suas atuações sobre o tema da sustentabilidade. Os objetos qualitativos sobre sustentabilidade foram extraídos dos sites das empresas para que fosse possível uma análise quantitativa, por meio dos cálculos dos frames, para facilitar a comparação de diferentes informações divulgadas em diferentes sites.

Pela análise dos frames, foram comparados diferentes conhecimentos de diferentes agentes que, ao caso, são duas empresas do setor de Telefonia. Ao extrair objetos em sites e, posteriormente, inseri-los no frame MORPH, foram gerados scores, dessa maneira, analisadas duas perspectivas de adição de valor:

- Variáveis qualitativas (objetos sobre sustentabilidade);

- Variáveis quantitativas (scores e receitas de vendas).

A pesquisa se limitou de informações divulgadas pelas empresas em seus sites e pelo site da BM\&F BOVESPA (2013). Não foi verificado se o que é divulgado, realmente, é implementado pelas empresas. Não foi feita uma pesquisa que descrevesse o significado de cada objeto, mas considero o meu juízo de valor apresentando os modelos das empresas, de acordo com o contexto de cada empresa. 
Outras aplicações podem ser consideradas pela direção do desenvolvimento de investigações e pelo contexto da governança corporativa das empresas de Telefonia. O desenvolvimento investigações de campo, por entrevistas, poderia confirmar ou não o que as empresas divulgam em seus sites e em outros meios.

\section{REFERÊNCIAS}

BADDELEY, A. Working Memory. Sciences de la Vie: Comptes Rendus de l'Académie des Sciences, v. 321, n. 2-3, p. 167-173, fev.-mar. 1998.

BARON, R. A.; SHANE, S. A. Empreendedorismo: Uma visão do processo. São Paulo: Thomson Learning, 2007.

BELL, D. E.; KEENEY, R. L.; RAIFFA, H. Conflicting objectives in decisions. New York: John Wiley, 1997.

BM\&F BOVESPA. Em Boa Companhia. Disponível em: <http://www.bmfbovespa.com.br/wrs/index.asp>. Acesso em: 22 abr. 2013.

CASTELLS, M. A galáxia da internet: reflexões sobre a internet, os negócios e a sociedade. Rio de Janeiro: Jorge Zahar Editora, 2003.

COSTA, F. M. Aquisição de conhecimento de agentes textuais baseada em MORPH. Limeira: UNICAMP, 2012. Originalmente apresentada como dissertação de mestrado, Universidade Estadual de Campinas, 2012.

DRUCKER, P. F. The Drucker Lectures: Essential Lessons on Management, Society and Economy. New York: McGraw-Hill, 2010.

ELKINGTON, J. The Triple Bottom Line. In: RUSSO, M. V. (Org.). Environmental Management: Readings and Cases. 2 ed. Estados Unidos: Sage Publication, 2002.

GARDINER, P. C.; FORD, A. Which policy run is best and who says so? TIMS Studies Management Sciences, Amsterdam, v. 14, p. 241-257, 1980.

GATHERCOLE, S. E. Models of verbal short-term memory. In: CONWAY, M.A. (Ed.). Cognitive models of memory. Cambridge: MIT Press, 1997.

GOFF, L. M.; ROEDIGER, H. L. Imagination inflation for action events: Repeated imaginings lead to illusory recollections. Memory \& Cognition, v. 26, n. 1, p. 20-33, 1998.

LAPP, Christian; OSSIMITZ, Güenther. Proposing A Classification Of Feedback Loops In Four Types. Scientific Inquiry, v. 9, n. 1, p. 29-36, jun. 2008.

MARION, J. C. Reflexões sobre ativo intangível. Disponível em: $<$ https://www.univem.edu.br/intranet/cad_cursos/arquivos/003-arqui-Ativo\%20Intang\%C3\%ADvel\%20-

\%20Prof.\%20Marion.pdf>. Acesso em: 22 abr. 2013.

MATLIN, M. W. Psicologia Cognitiva. Rio de Janeiro: LTC, 2004.

MORECROFT, J. D. W.; STERMAN, J. D. (Eds.). Modeling for Learning Organizations. Portland: Productivity Press, 2000.

NONAKA, I. The knowledge-creating company. Harvard Business Review, Boston, v. 69, n. 6, p. 96-104, jul.-ago. 2007.

PACE, E. S. U.; BASSO, L. F. C.; SILVA, M. A. Indicadores de desempenho como direcionadores de valor. Revista de Administração Contemporânea, Curitiba, v. 7, n. 1, p. 37-65, jan.-mar. 2003.

PERRIG, A.; CHAN, H. ACE: An Emergent Algorithm for Highly Uniform Cluster Formation. Lecture Notes in Computer Science, v. 2920, p. 154-171, jan. 2004.

PORTER, M. On Competition. Boston: The Harvard Business Review Book Series, 2008.

ROMEIRO, A. R. Economia ou economia política da sustentabilidade? 2001. Disponível em: $<$ http://cursa.ihmc.us/rid=1GM431YJX-G9XCVN-

S9/economia\%20ou\%20economia\%20da\%20pol\%C3\%ADtica\%20da\%20sustentabilidade.pdf>. Acesso em: 22 abr. 2013.

SAATY, T. L.; SODENKAMP, M. The Analytic Hierarchy and Analytic Network Measurement Processes: The Measurement of Intangibles In: ZOPOUNIDIS, C.; PARDALOS, P. M. Handbook of Criteria Analysis. Heidelberg: Springer, 2010.

SANTOS, S. P.; BELTON, V.; HOWICK, S. Enhanced performance measurement using OR: a case study. Journal of the Operational Research Society, v. 59, n. 6, p. 762-775, 2008.

SENGE, P. M. A quinta disciplina: a arte e prática da organização que aprende. São Paulo: Best Seller, 2009.

SILVEIRA, A. D. M. Governança Corporativa, Desempenho e Valor da Empresa no Brasil. São Paulo: USP, 2002.

Originalmente apresentada como dissertação de mestrado, Universidade de São Paulo, 2002.

TELEFÔNICA VIVOa. RC e Sustentabilidade. Disponível em: <http://www.telefonica.com.br/institucional/sobre-atelefonica/rc-e-sustentabilidade>. Acesso em: 22 abr. 2013. 
TENPENNY, P. L.; SHOBEN, E. J. Component processes and the utility of the conceptually-driven/data-driven distinction. Journal of Experimental Psychology: Learning, Memory, and Cognition, v. 18, n. 1, p. 25-42, jan. 1992.

TIM. Quem Somos. Disponível em: <http://www.tim.com.br/sc/sobre-a-tim/institucional/quem-somos>. Acesso em: 22 abr. 2013.

TOMÉ, I. M. Modelo para análise da sustentabilidade empresarial com base em MORPH. Limeira: UNICAMP, 2012. Originalmente apresentada como dissertação de mestrado, Universidade Estadual de Campinas, 2012.

TOMÉ, I. M.; BRESCIANI, L. P. Explicitação e análise de modelos de sustentabilidade de empresas de gestão ambiental baseados em MORPH. REUNIR: Revista de Administração, Contabilidade e Sustentabilidade, Sousa, v. 5, n. 1, p. 21-38, 2015.

TVERSKY, A.; KAHNEMAN D. The Framing of Decisions and the Psychology of Choice. Science Magazine: American Association for the Advancement of Science, v. 211, n. 4481, p. 453-458, jan. 1981.

UNITED NATIONS. DEPARTMENT OF ECONOMIC. Indicators of sustainable development: Guidelines and methodologies. New York: United Nations Publications, 2001.

ZAMBON, A. C. Uma contribuição ao processo de aquisição e sistematização do conhecimento multiespecialista e sua modelagem baseada na Dinâmica de Sistemas. São Carlos: UFSCAR, 2006. Originalmente apresentada como tese de doutorado, Universidade Federal de São Carlos, 2006. 
